\title{
The Relation between God and the World in the Pre-Critical Kant: Was Kant a Spinozist?
}

\author{
NOAM HOFFER \\ Indiana University Bloomington \\ Email: noamhoffer@gmail.com
}

\begin{abstract}
Andrew Chignell and Omri Boehm have recently argued that Kant's pre-Critical proof for the existence of God entails a Spinozistic conception of God and hence substance monism. The basis for this reading is the assumption common in the literature that God grounds possibilities by exemplifying them. In this article I take issue with this assumption and argue for an alternative Leibnizian reading, according to which possibilities are grounded in essences united in God's mind (later also described as Platonic ideas intuited by God). I show that this view about the distinction between God's cognition of essences as the ground of possibility and the actual world is not only explicitly stated by Kant, but is also consistent with his metaphysical picture of teleology in nature and causality during the pre-Critical period. Finally, I suggest that the distinction between the conceptual order of essences embodied in the idea of God and the order of the objects of experience plays a role in the transition into the Critical system, where it is transformed into the distinction between the intelligible and the sensible worlds.
\end{abstract}

Keywords: God, Only Possible Argument, possibility, Leibniz, essences, Platonic ideas

\section{Introduction}

It has been recently suggested by several authors that Kant's pre-Critical proof for the existence of God (presented mainly in The Only Possible Argument in Support of a Demonstration of the 
Existence of God from $1763^{1}$ ) entails a Spinozistic conception of God. ${ }^{2}$ Such a conception consists in substance monism - the view that there is only one substance, God, and that all other things are modes of the one substance. According to Kant's pre-Critical argument, ${ }^{3}$ God is the single ground of all possibility. The attribution of Spinozism to Kant is derived from two further interpretative claims about Kant's argument: 1. the grounding relation between God and possibilities is a relation of exemplification. 2. Kant is (or should have been) committed to the view that all possibilities are exemplified in God, and not only those of maximal realities but also of lesser degrees or derived realities. Following these two claims, since God exemplifies all possibilities, the actual world inheres in God.

In this article I will provide an alternative for claim 1, the thesis that God grounds possibilities by exemplifying them, and thereby reject the basis for a Spinozistic reading. Instead, I will suggest that possibilities are grounded in essences united in God's mind, later described also as Platonic ideas intuited by God. Thus according to my reading, actual objects are not modes of God and the actual world does not inhere in God. I will show that this view about the distinction between God and the world is not only explicitly stated by Kant, but is also consistent with his general metaphysical picture during the pre-Critical period and the role God plays in it, from the New Elucidation through The Only Possible Argument and the Inaugural Dissertation. Yet the Spinozistic reading has a grain of truth in it, as there is a kind of monism entailed by Kant's conception of God. However, it is not substance monism but rather what I would call conceptual monism, the view that all concepts of realities, i.e. essences, must be thought of as belonging to one comprehensive whole.

By arguing for this interpretation, I can show the continuity between the pre-Critical and the Critical conception of God. I suggest that the distinction between the conceptual order of 
essences united in God's intellect and the order of objects in the actual world develops into the Critical distinction between the intelligible world and the sensible world. With the transition to the Critical system, Kant developed this distinction by articulating the relations between the metaphysical structure of each order and the epistemological conditions applicable to it. While the form of the sensible world is derived from the conditions of possible experience, the notion of an intelligible world expresses the demand of reason for an ultimate metaphysical ground but is in principle unknowable. In this way the pre-Critical conception of God as the ground of possibility is transformed into a regulative idea of reason.

I proceed as follows. In the first part I present the Spinozistic interpretations of Kant's possibility proof as following from the thesis that God grounds possibilities by exemplifying them. Even though this thesis is presupposed in much of the literature, only in the Spinozistic readings does it receive a thoroughgoing justification. It is therefore important to lay it out in its most developed form as a foil for my alternative reading. In the second part I develop a Leibnizian interpretation according to which possibilities are grounded in essences in God's mind. I first present the textual evidence for reading Kant's argument in this way, and then show that this interpretation fits well with other doctrines held by Kant in the pre-Critical period about teleology in nature and causality. Finally I focus on Kant's appropriation of Platonic ideas in his explication of divine cognition and argue that it both clarifies the metaphysical account about the ground of possibility and attests to the continuity in Kant's thought by showing how the initial Leibnizian conception of God is transformed into a regulative idea designating the intellectual intuition of the intelligible world. 


\section{Spinozism in the Possibility Proof}

I present here very briefly the main elements of Kant's argument in OPA in order to show what leads some interpreters to argue that it entails a Spinozistic conception of God. ${ }^{4}$ The argument begins with an examination of the notion of possibility and distinguishes between two conditions for something to be possible. First, there can be no contradiction in the concept of the thing. Contradictory predicates render a thing logically impossible. The lack of contradiction is the logical or formal ground of possibility (OPA 2: 77). The formal ground is however only a necessary condition, not a sufficient one. Since non-contradiction is a relation, there must be things that stand in that relation. In order for predicates to stand in the logical relation of noncontradiction they must themselves have some content, designate something that can be thought. This thinkable content, the datum of thought, is the material or real ground of possibility (OPA 2: 78). Without such content that can be 'given' to thought, the predicates are mere 'empty words'. Thus for something to be possible these two conditions must be fulfilled: the material condition its predicates must be must have content; and the formal condition - the predicates must not contradict each other. ${ }^{5}$

The formal condition is obvious. But what is required for satisfying the material condition, i.e. what does it take for a predicate to designate something, to have content? Kant asserts that something has to exist in order to be given for thought, hence in order to be possible: 'The internal possibility of all things presupposes some existence or other' (2: 78). The datum for thought that renders something materially possible (and not only logically possible) has to be given through something existing, something which grounds the possibility.

Kant uses these considerations to prove that there is some necessarily existing being. For anything to be possible something else must exist, thus all possibility relies on something actual. 
If nothing exists, nothing can be given for thought, and thus nothing is possible. Kant maintains that it is impossible for nothing to be possible, and therefore there is something that exists necessarily. After establishing the necessary existence of some being grounding all possibility, he goes on to prove first that necessarily there is only one being grounding all possibility, i.e. it is unique, and then that its attributes match the concept of God: it is simple, immutable, eternal and intelligent.

Some of the moves in the proof are questionable, especially the step proving the uniqueness of the necessary being, and one possible solution of it involves a Spinozistic reading. ${ }^{6}$ However, I will begin by discussing the very first step of the argument about the material condition of possibility, the principle that every possibility is grounded in something existing, because a certain understanding of it forms the basis for the Spinozistic reading. In what way does existence ground possibility?

Chignell, following Adams, presents two ways of grounding possibilities in existence as a contrast between Leibniz and Kant (Adams 2000: 427; Chignell 2012: 643). Leibniz too held the principle that possibility must be grounded in existence. ${ }^{7}$ For example in the Monadology:

For if there is reality in essences or possibles, or indeed, in eternal truths, this reality must be grounded in something existent and actual. (Monadology §44)

Similarly to Kant, Leibniz used this consideration for proving the existence of God, as that without which nothing is possible:

without him there would be nothing real in possibles, and not only would nothing exist, but also nothing would be possible. (Monadology §43)8

Leibniz identifies necessary truths with truths about possibilities or essences, and argues that these truths must be grounded in something existing. The way God grounds possibilities is 
through his thought: 'God's understanding is the realm of eternal truths or that of the ideas on which they depend' (ibid).

According to Adams and Chignell Kant diverges from Leibniz on this last point, as for Kant possibilities are not grounded in virtue of God thinking them, but in virtue of exemplifying them (Adams 2000: 427; Chignell 2009: 185, 2012: 636). Call this thesis Exemplification. Most other interpretations of OPA (but not all) presuppose Exemplification, usually without stressing the divergence from Leibniz. ${ }^{9}$ I argue that if Exemplification is explicitly endorsed then Spinozism is a possible outcome of Kant's argument. This follows from these considerations:

1. Every possibility is grounded in an actual being (the grounding requirement)

2. Possibilities are grounded only by being exemplified in an actual being

3. Every possibility must be exemplified (from $1 \& 2$ )

4. God is the single ground of all possibilities (this is the outcome of the possibility proof)

5. God exemplifies all possibilities (from $3 \& 4$ )

6. The actual world is a certain set of things exemplifying possibilities

7. Things are individuated by the possibilities they exemplify (the identity of indiscernibles)

8. The actual world is identical with God, or is a subset of God.

Accepting (8) means accepting substance monism, or Spinozism.

Note that the conclusion of substance monism requires Exemplification in a strong form as in (2), namely, that all possibilities are grounded by exemplification. According to other interpretations of the possibility proof, only some possibilities are grounded by exemplification, call them the fundamental possibilities, while others, call them derivative possibilities, are grounded in other ways, for example by being causal consequences of the fundamental 
possibilities exemplified in God, ${ }^{10}$ or by being derived from logical relations between fundamental possibilities. ${ }^{11}$

Chignell and Boehm present different arguments in support of the strong thesis (2) that all possibilities are exemplified by God. Neither of them claims that it is an explicit premise in Kant's argument, rather that it is entailed by a logically sound and textually accurate reconstruction. Yet one might question whether the grounding relation between God and possibilities should be thought of as a relation of exemplification at all, and in the next section I will pursue this alternative way of thinking about this relation the grounding. Thus I will discuss the details of their arguments only insofar it is required for examining the viability of Exemplification. In order to do that I will first present the textual evidence for it.

The main evidence comes from the following passage:

[the] relation of all possibility to some existence or other can be of two kinds. Either the possible can only be thought in so far as it is itself real, and then the possibility is given as a determination existing within the real; or it is possible because something else is real; in other words, its internal possibility is given as a consequence through another existence. (OPA 2: 79)

And later again:

The data of all possibility must be found in the necessary being either as determinations of it, or as consequences which are given through the necessary being as the ultimate real ground. (OPA 2: 85)

We see here two ways of grounding possibilities, either by determinations of God or by consequences of God. The claim of Exemplification stems from a certain understanding of how a ‘determination’ (Bestimmung) grounds possibility. A determination is a characteristic mark, something that can be predicated of a thing or a concept so that it determines it one way or another: '[t]o determine is to posit a predicate while excluding its opposite’ (NE 1: 391). According to the grounding principle, in order for a determination of something to be possible something real has to be the 'datum' that could be 'given' for the predication (OPA 2: 78). Some 
predicates are complex and can be analysed into more simple constituents. But at the end of the analysis the simple elements must signify something real. For example the concept of a body can be analysed as including 'extension, impenetrability, force' (OPA 2: 80-1). If these are unanalysable simple predicates they must signify something real. Without the ‘datum’ the alleged possible determination is nothing but an 'empty word' that does not signify anything. The talk about signifying (bezeichnen, bedeuten) suggests that the grounding relation between a possibility and an existing thing is a reference relation. Thus a possible way to understand the relation grounding the possibility of predicates is as follows: a predicate is possible if its concept refers to an actual predicate of an existing thing. Therefore if $\mathrm{F}$ is a possible unanalysable (fundamental) predicate then necessarily there is something which exemplifies F. Since the argument is supposed to demonstrate that all possibilities are in the final analysis grounded in one being, i.e. God, God exemplifies all fundamental predicates.

Yet this conclusion from Exemplification applies only to the fundamental predicates. Spinozism requires that all possible predicates, including the derivative ones, are exemplified in God, so that the totality of actual things would also inhere in God. Recall Kant's statement that some possibilities are grounded in the determinations of something real, while other are grounded in consequences of those determinations. If consequences inhere in God and ground possibilities by exemplifying them, then all possibilities are exemplified in God, either directly or derivatively. Otherwise, the derivative possibilities can still be grounded in the Leibnizian way as ideas in God's mind or in another way, for example by being causal consequences of God's powers.

Boehm justifies the Spinozistic interpretation first by arguing that the relation between determinations and their consequences is not a causal relation but a relation of inherence, and 
secondly that consequences signify not mere general possibilities but existing finite things. Boehm's reason for rejecting the causal interpretation is that making things causally dependent on God makes the possibility proof collapse into the cosmological proof, which Kant explicitly rejects. The proof arrives at the conception of God from the grounds of the possibility of things, and not from the first cause of their existence as does the cosmological proof. ${ }^{12}$

Additionally, Boehm finds textual evidence that Kant held the position that all things inhere in God (Boehm 2012: 305). In many places when discussing the conception of God, Kant describes individual things as limitations of one substance. ${ }^{13}$ In some places Kant even relates this mode of the inherence of things as limitations of one substance to Spinozism (Boehm 2012: 306). Thus Boehm concludes that the possibility proof implies that all individual things inhere in God and hence there is only one substance. Under this reading, Kant's determinations of God, the fundamental properties, are similar to Spinoza's attributes of God, while the consequences of the determinations are parallel to Spinoza's modes, the limitations of the infinite that constitute individual things. ${ }^{14}$

Chignell provides a further argument in support of the thesis that God must exemplify all possibilities in contrast with the Leibnizian alternative that God grounds possibilities by thinking them. Recall Kant's distinction between two conditions of possibility, the formal condition of the lack of contradiction and the material condition that something must be given as a content for thought. Chignell extracts another condition implicit in OPA and in other pre-Critical texts. This condition is based on Kant's anti-Leibnizian claim that there are relations of opposition or repugnance between real things which are not logical relations of contradiction. For example the relation between forces in opposite directions is a relation of opposition that cancels the movement of an object (OPA 2: 86). Another kind of opposition is between incompatible 
properties that cannot be instantiated in the same things, even though this opposition cannot be analysed as a logical contradiction. A logical contradiction ensues from applying a predicate and its negation to the same thing. According to Kant, however, there are positive predicates which are still incompatible. For example: 'The impenetrability of bodies, extension and such like, cannot be attributes of that which has understanding and will' (OPA 2: 85). From the notion of real repugnance, Chignell introduces another condition of possibility which he calls 'harmony' a thing is possible only if its predicates are harmonious (not in real opposition) with one another (Chignell 2009: 174, 2012: 647).

Since harmony is a condition of possibility it must also be grounded in God, which is the ground of all possibility. And since harmony is not a logical relation, it cannot be grounded in thought but only through exemplification. In other words, the ground of the harmony of all harmonious predicates is their being exemplified together in one being, God. According to Chignell, the requirement for grounding harmony can be used to vindicate the crucial step of Kant's argument that the ground of all possibility is unique, meaning that possibility cannot be grounded in a plurality of objects and therefore there is only one necessary being. ${ }^{15}$ Moreover, he argues that Kant's explicit arguments for uniqueness fail, and therefore the only way to save Kant's argument is by appealing to the harmony requirement (Chignell 2012: 656-7). The uniqueness of God can be vindicated in the following manner: since the grounding of harmony requires co-exemplification in one being, the grounding of possibilities cannot be divided between several beings. Thus there is a single being grounding the harmony of possibilities by co-exemplifying them. ${ }^{16}$

According to Chignell, the requirement to ground real harmony in actuality is also what explains the difference between Kant and Leibniz. For Leibniz modal facts are grounded in 
virtue of being thought by God. But for Kant thought can only track logical relations of noncontradiction as a condition of possibility. Thus the distinction between the formal ground and the material ground of possibility, which includes also the grounding of harmony, is incompatible with Leibniz's solution. In the Critique of Pure Reason Kant argues repeatedly that human discursive thought is not sufficient to track real possibility, in contrast with logical possibility. Chignell argues that this restriction extends also to divine thought. ${ }^{17}$ Furthermore, in later writings Kant characterizes the divine mind as an intuitive intellect representing immediately all details of reality while creating it at the same time, thus not having at all the kind of representations needed for representing un-actualized possibilities.

The Spinozistic reading of Kant depends on identifying the material ground of possibilities with their exemplification in an existing being. While Boehm relies mainly on textual evidence for this interpretation, Chignell, through the formulation of the harmony requirement, contends that without Exemplification Kant's argument does not go through. What I will reject is the basic premise that possibilities are grounded by being exemplified. In the next section I will provide an alternative to Exemplification and show that it is both consistent with the course of the argument, and that it coheres better with other elements in Kant's pre-Critical system regarding teleology and causality.

\section{God's Mind as the Ground of Possibilities}

\subsection{Leibnizianism in the Possibility Proof}

In contrast with Exemplification, on which the Spinozistic reading is based, I will argue that possibilities are grounded in essences represented in God's intellect. Mapping my reading onto Kant's distinction between determinations of God and consequences of those determinations, or 
the above mentioned distinction between fundamental and derivative possibilities, I argue that there is one determination of God, that of being a mind, which is the ultimate ground of all possibility. Particular possibilities and the systematic order between them are grounded in essences which in virtue of being represented are consequences of God's mind. The other fundamental determinations of God, uniqueness and simplicity, characterize the system of derivative possibilities as a single and comprehensive totality.

If this reading is correct, then unlike what was suggested above, Kant does not diverge significantly from Leibniz about the grounding of possibilities. ${ }^{18}$ Indeed, Kant does not present his position about it in OPA as a criticism of Leibnizianism. Where Kant diverges from the Leibnizians in OPA is in the claim that the possibility proof is the only possible proof for the existence of God, and that the other proofs endorsed by them are fallacious. Regarding Kant's criticism of rationalistic theology, we should notice that the refutation of the ontological proof presupposes the Leibnizian distinction between God's understanding as the ground of possibility and his volition as the ground of actuality. Kant's explication for what lies at the heart of the refutation, the claim that existence is not a real predicate, is that God can think a concept of a possible thing (such as Julius Caesar) as fully determined regarding all predicates without thereby choosing to create this object as part of the actual world (OPA 2: 72). It thus seems that Kant viewed his criticism as internal to the Leibnizian system by showing that the ontological proof does not cohere with the distinction between divine cognition and creation which also explains the distinction between possibility and actuality.

Regarding the possibility proof itself, the continuity between Kant's argument and the Leibnizian system can be noticed from the terminology used at the beginning of the argument: 'The internal possibility of all things presupposes some existence or other' (OPA 2: 78; emphasis 
mine). In Baumgarten’s Metaphysics ‘inner possibility’ is a common term that plainly means ‘essence’ (also ‘nature ‘or 'formal ground’, Metaphysica §40). Wolff also equates ‘possibility’ with essence, that which makes a thing possible as what it is (Deutsche Metaphysik §35). Similarly to Leibniz, Wolff and Baumgarten maintain that all essences are grounded as representations in God’s mind (Deutsche Metaphysik §975; Metaphysica §868). In an early version of the possibility proof Kant states that essences 'consist in inner possibility' (NE 1: 395). It is therefore plausible that Kant used the term 'internal possibility' in a way that was familiar to his readers from the Leibnizian philosophy.

Yet one can argue that the reality of essences is grounded by being exemplified in God and not by being represented by God. Furthermore, it could be argued that only the instantiation of properties can satisfy the content requirement that something must be 'given' for thought. In other words, the objection is that a thought can have content only if it refers to a non-intentional reality outside of it, and therefore Kant's introduction of the material condition of possibility is exactly such a criticism of the Leibnizian option of grounding possibilities in God's mind. But there is no textual ground for taking Kant's introduction of the logical/material distinction as a criticism of Leibniz. Instead, I suggest viewing it as making explicit a presupposition in Leibniz's own proof from eternal essences in the Monadology. Regarding the content of modal propositions, Leibniz explicitly maintained, for example, that the truth of the proposition expressed by 'the impossibility of a square larger than an isoperimetric circle' is grounded 'in that in which is found the nature of the circle, the square, and the other things; that is, in the subject of ideas, or God'. ${ }^{19}$ Since true propositions necessarily have content, the content requirement of the above proposition is for Leibniz satisfied by the 'natures' of a circle and square, which are ideal entities in God's mind. There is no reason to think that Kant had any 
objection to this position, and as I will show, it is exactly this way of appealing to essences in God's mind as the ground of modal truths which constitutes for Kant the usefulness of the possibility proof and the metaphysical role of the conception of God in general.

\subsection{God's Mind in the Possibility Proof}

In order to support this reading, let us first examine what is meant by the grounding of a possibility in a determination of God. The examples for this grounding relation are rather sketchy. Kant admits that providing examples for such abstract matters is hard: '[e]lucidatory examples cannot yet be suitably furnished here' and adds that '[t]he nature of the only subject which could serve as an example in this reflection ought to be considered first of all' (OPA 2: 79). This means that providing an example for the grounding of possibilities is feasible only by first establishing the nature of the being grounding all possibility, i.e. God. I will suggest that Kant first had to show that God is a mind before we get the full account of how God grounds possibilities. In light of this comment we can read the example of the 'fiery body' (OPA 2: 80) as a rough illustration of the distinction between the logical and material grounds of possibility, showing that after ascertaining the non-contradiction between the fundamental predicates of a thing, we can still ask what grounds these predicates with regard to how their content is 'given'. But we should not read the example to show that the basic constituents of the concept of a fiery body, such as the concepts of extension and impenetrability, are exemplified in God, as Kant explicitly rejects this analysis: 'The impenetrability of bodies, extension and such like, cannot be attributes of that which has understanding and will' (OPA 2: 85).

The only determinations Kant explicitly attributes to God are uniqueness, simplicity, immutability and finally being a mind (OPA 2: 83-7); and the only explicit example of a possibility grounded in God is of the last determination, being a mind. Kant elaborates on this 
relation of grounding in his arguments for God being a mind, i.e. having understanding and will. First, Kant contends that understanding and will can co-exist in one being (OPA 2: 87). The second point resembles Descartes’ argument in the Third Meditation. Since understanding and will are positive properties which cannot be derived from other properties, and since the ground of a possibility cannot have less reality than the consequence, and since minds are possible (as there are actual minds), then the ground of all possibilities also has the properties of a mind (OPA 2: 88).

For the present purposes, the more interesting argument is the last one, in which God's having an intellect is inferred from the relations of 'order, beauty and perfection in all that is possible', as no other explanation for their existence seems sufficient (ibid). ${ }^{20}$ Finding evidence for the intelligence of the first cause in the order of nature is a familiar theme, but Kant's specific take on this issue in OPA sheds light also on the grounding of possibilities. The harmony and order of nature is the subject of the lengthy second part of the book, titled 'concerning the extensive usefulness peculiar to this mode of proof in particular' (OPA 2: 93-155). The title means that the section does not comprise a standalone proof for the existence of God, but rather it exemplifies the conduciveness for the investigation of nature of the very same conception of God advanced in the first part. The study of nature thus provides further evidence for the soundness of the proof. One of Kant's goals in the second part of the essay is to reject explanations of purposiveness in nature as resulting from a deliberate divine action. Instead, the correct way to think about the harmony in nature is as a result of the necessary laws discoverable by the natural sciences. ${ }^{21}$ In order to explain this account Kant appeals to the following distinction:

I designate that dependency of a thing upon God moral when God is the ground of that thing through his will. All other dependency is non-moral. Accordingly, if I assert that God contains the 
ultimate ground even of the internal possibility of things, everyone will easily understand that this can only be a non-moral dependency, for the will makes nothing possible; it merely decides upon what is already presupposed as possible. In so far as God contains the ground of the existence of things, I admit that this dependency is always moral; in other words, things exist because God willed that they should exist. (OPA 2:100 emphases mine)

Kant makes the distinction between the existence of things in the created world, which is 'morally' dependent on God, i.e. through his will, and the ground of the internal possibility (essence) of things, which inheres necessarily in God. In this he echoes the Leibnizian position against Cartesian voluntarism regarding necessary truths ${ }^{22}$ as well as the related doctrine about divine creation as a choice from a range of possibilities. ${ }^{23}$

The distinction between what is grounded necessarily in God (essence) and what follows contingently from God's choice (existence) is important for Kant for establishing the right use of teleological principles in science. Science should seek purposiveness in the harmony between laws of nature and not in the existence of individuals. Kant does not explain explicitly the relation between essences as grounded in divine thought, and laws of nature as discoverable by science, but it is clear that for Kant the unity of the laws of nature bears evidence for the unity of essences. This can be inferred from the headings in the first reflection of section 2, such as 'unity in the manifold of the essences of things is demonstrated by appeal to the properties of space' (OPA 2: 93) and 'unity in the manifold of the essences of things proved by reference to what is necessary in the laws of motion' (OPA 2: 96). Kant regards the laws of geometry as derivable from the essence of space, and the laws of motion as derivable from the essence of matter. ${ }^{24}$ The overall unity in all of science is therefore related to the relations between all essences.

Thus Kant maintains that this way of thought regarding the harmony of laws of nature as a consequence of the unity of essences leads to the same conception of God advanced in the argument from the grounding of all possibility: 
Our mature judgement of the essential properties of the things known to us through experience enables us, even in the necessary determinations of their internal possibility, to perceive unity in what is manifold and harmoniousness in what is separated ... Our purpose from now on will be to see whether the internal possibility of things is itself necessarily related to order and harmony, and whether unity is to be found in this measureless manifold, so that, on this basis, we could establish whether the essences of things themselves indicate an ultimate common ground. (OPA 2: 92; emphases mine)

The fact that harmony is discovered at the level of the essences of the objects of nature, and not only in the contingent arrangement of particular things, points to a single ground of all essences, i.e. the conception of God as the ground of all possibility.

How are the essences of things related to God, the ground of all possibility? Kant is not fully explicit about this here, but he implies that it is related to the determination he proved earlier to belong to God, the property of being a mind, or having understanding and will. We can see it in the way Kant summarizes what is entailed by his proof:

it is further apparent from the argument we have recommended that all the essences of other things and the real element of all possibility are grounded in this unique being; in it are to be found the highest degree of understanding and will; and that is the greatest possible ground. (OPA 2: 91; emphases mine)

This can help us interpret more concretely what Kant means by the dictum 'all possibility is given in something actual, either as a determination existing within it or as a consequence arising from it'. The determination in question, which is 'the greatest possible ground', is being a mind, and the consequences that ground particular possibilities are essences united in God's mind. ${ }^{25}$ Since the consequences are essences and not instances of properties or individual things there is no reason to identify this conception of God with Spinozism, i.e. a conception of God as containing within it the actual world. On the other hand it is compatible with the Leibnizian position found also in Kant that necessary truths are grounded in the content of God's understanding and that contingent truths about the existence and arrangement of things in the world are grounded causally in God's will. 
Additionally, we can see how God's other determinations, the ontological predicates ${ }^{26}$ of uniqueness, simplicity, immutability and eternity play a role in this picture of the grounding of possibilities. The immutability and eternity of God correlate with the lawfulness of nature, the fact that phenomena exhibit unchanging regularities. The harmony between essences (and laws of nature derivable from them) points to their single ground, which correlates with there being only one God (uniqueness), not composed of independent parts (simplicity). Since this metaphysical picture makes the distinction between God as the ground of the totality of essences and the actual world as the totality of individual things, it is not a form of substance monism. But since all essences harmonize in virtue of being related to one ground, we might call it conceptual monism - the view that all essences should be conceived as belonging to one systematic whole. The linkage between the conception of God and the systematicity of nature continues into the Critical period even when the epistemic status of God is demoted from an object of a priori knowledge to that of a mere regulative idea. Hence the idea of God is the regulative idea guiding the legitimate interest of reason in finding systematicity in nature:

The idea of that being [God] ... means nothing more than that reason bids us consider every connection in the world according to principles of a systematic unity, hence as if they had all arisen from one single all-encompassing being. (A686/ B714)

\subsection{God as the Ground of Causal Relations}

In OPA the conceptual monism emerges in two ways: first from the $a$ priori construction of the conception of God as the single ground of all possibility, and second from the empirical evidence for harmony in nature. But there is no explicit argument why it is necessary for all essences to be interrelated in one system. An argument akin to that purpose can be found in Kant's pre-Critical discussion of causality, both in the beginning of his philosophical career in 1755 and in the culmination of the pre-Critical project in 1770. In the New Elucidation of 1755, Kant argues for the 'physical influx' theory of causality, the view that there is real causal interaction between 
physical substances. ${ }^{27}$ This is expressed in the 'principle of succession': 'No change can happen to substances except in so far as they are connected with other substances; their reciprocal dependency on each other determines their reciprocal changes of state' (NE 1: 410). But for there to be real interaction, Kant states that another principle that must be fulfilled, the 'principle of co-existence':

Finite substances do not, in virtue of their existence alone, stand in a relationship with each other, nor are they linked together by any interaction at all, except in so far as the common principle of their existence, namely, the divine understanding, maintains them in a state of harmony in their reciprocal relations. (NE 1: 413)

Kant argues that the possibility of relations between substances cannot be derived from the concept of a substance, and therefore a common ground for all substances must be presupposed, i.e. God. Kant is rather vague on how the common ground makes relations possible, but what is clear is that it involves God representing the relations between substances:

If they are conceived as related in God's intelligence, their determinations would subsequently, in conformity with this idea, always relate to each other for as long as they continued to exist ... the reciprocal connection of substances requires that there should be, in the effective representation of the divine intellect, a scheme conceived in terms of relations. (NE 1: 414)

It is important to note that in this picture God does not represent the particular states of interacting substances, but the relations between their states as relations determined by general laws. This way of grounding causal relation in God is made clearer by considering Kant's rejection of other theories of causality, pre-established harmony and occasionalism. In both of these theories causal relations are not real but are reduced to non-relational states. But the defect that Kant finds in them is that by over-complicating the account of causality they lose track of the lawfulness of the causal relations. Regarding pre-established harmony Kant maintains that 'God does not make use of the craftsman's cunning devices, carefully fitted into a sequence of suitably arranged means designed to bring about a concord between substances'; regarding occasionalism he states that 'the divine act does not need to be determined, now one way, now 
another, according to circumstances'. Instead, 'reciprocal interaction is established by means of those determinations which attach to the origin of their existence' (NE 1: 415). By this I understand Kant to argue that causal relations are as real as the original determination of things, i.e. their essences. And since relations cannot be grounded in essences separately, they must be grounded in one being, God. Yet the dependence of the lawfulness of causal relations on God's representation of universal essences is compatible with the reality of physical influx, i.e. reality of causal relations between particular objects in the physical world.

The grounding of causal relations in universal causal laws united in God is argued for in greater detail in the Inaugural Dissertation of 1770 . Kant begins by discussing the concept of a world in general and distinguishes between the matter of the world, as the contingent collection of individual substances in it, and the form of the world as the necessary general principles uniting all things by coordinating them (ID 2: 389-90). He argues that without such principles we could group representations together, but that would not amount to a representation of a whole. Since what is at issue is the essential unity of a world and not a contingent state of existing in one world, the form of the world is related to the possible interactions between substances, i.e. universal laws governing the relations between things: ${ }^{28}$

the connection, which constitutes the essential form of a world, is seen as the principle of the possible influences of the substances which constitute the world. For actual influences do not belong to the essence but to the state, and the transeunt forces themselves, which are the causes of the influences, suppose some principle by which it may be possible that the states of the several things, the subsistence of each of which is nonetheless independent of that of the others, should be mutually related to one another as states determined by a ground. (ID 2: 390; emphases mine) We see here a distinction between the states of contingent substances and the principles which govern all their possible interactions and give them a necessary unity. Thus the ground of possible states lies in some universal laws derivable from essences. As in other places discussed above, Kant relates the ground of the lawful unity of things to God. This is evident through the 
novel distinction introduced first in the Dissertation between the sensible world and the intelligible world. The sensible world is the world as representable by sensibility, whose unifying principles are the forms of intuition of space and time. The intelligible world is the world as representable by the intellect, i.e. solely by conceptual means. Thus the unity sought for the intelligible world is the conceptual unity of the essences of substances, a conceptual ground for the possibility of multiple substances to be related in one world:

We are contemplating the world in respect of its form, that is to say, in respect of how, in general, a connection between a plurality of substances comes to be, and how a totality between them is brought about. (ID 2: 407)

When discussing the unifying principle of the intelligible world, similarly to the New Elucidation, the concept of God comes into play as the single ground both for the actuality of the world and the unity of all essences:

the UNITY in the conjunction of substances in the universe is a corollary of the dependence of all substances on one being. Hence, the form of the universe is testimony to the cause of its matter, and only the unique cause of all things taken together is the cause of its entirety, and there is no architect of the world who is not also, at the same time, its Creator. (ID 2: 408)

We can glean from this the distinction between God as the cause of the actual world (a creator), and God as the conceptual ground of the essences in the world (an architect). This fits well with Kant's earlier distinction between God's mind as the ground of all essences, including the possible relations between them, and the actual world created through his will. Thus in the Dissertation we see a new systematic reason for maintaining the ontological distinction between God and the world as a distinction between the intelligible world as realm of immutable essences united in a divine mind and the changing states of things in the sensible world, which are sensibly unified spatio-temporally. ${ }^{29}$ Although this distinction between the unity of the realm of essences and the actual world does not have the same systematic grounding before 1770, I showed above that it is implicit in the New Elucidation argument for the role of God in Kant's 
version of physical influx, and in the 1763 appeal to harmony in nature as an expression of the conception of God put forward by the possibility proof. The Spinozistic reading, however, blurs this distinction which is central in Kant’s thought. But not only that, I believe that the interpretation presented above offers a better metaphysical explanation for the starting point of Kant's argument, that possibilities must have a ground. In order to show that, let us look at Kant's later remarks about divine cognition which directly relate to the sensible/intelligible distinction introduced in the Dissertation.

\subsection{Divine Cognition and Platonic Ideas}

The exact nature of God's mind as the ground of possibilities and the principle of the intelligible world becomes clearer in many remarks beginning from the early 1770's that identify the content of God's cognition with Platonic ideas. ${ }^{30}$ The references to Plato usually appear in the context of the distinction between sensible and intellectual intuition. In this context, Kant criticizes Plato for ascribing to human cognition the capacity for the latter, which amounts to mysticism. ${ }^{31}$ But what is also apparent is that the Platonic mode of knowledge is apt for characterizing divine cognition, and moreover, for the way Kant interpreted the Leibnizian conception of divine cognition. ${ }^{32}$ This is evident from the notes Kant added to the sections on God's mind in Baumgarten’s Metaphysics (Intellectus Dei. §§863-89) and from the lecture transcripts which also refer to these sections. ${ }^{33}$ In these remarks we find several characteristics of divine cognition. Divine cognition is archetypical, i.e. it cognizes the perfect essences or principles of things, in contrast with human knowledge which is ectypical, i.e. generalized from imperfect instances. While the latter depends on the existence of objects, the former is at the same time the capacity to produce them. For these reasons Kant identifies the representation of essences in God's mind with Plato's notion of ideas, in contrast with concepts of human understanding. 
How are Platonic ideas related to the grounding of possibilities? In a note delineating the taxonomy of representations, Kant defines 'idea' as 'conceptus archetypus, [which] contains the ground of the possibility of the object', and then adds 'God is the inhering subject of all ideas as the ens realissimum and also the first cause of everything contingent' (R2835, 16: 537; emphasis mine). We see here two ways God functions as a ground. First, God as the subject of all ideas grounds the possibility of things. As an intuitive intellect, God does not merely represent independently given ideas, but generates their reality (though not as an act of will). Since in Platonic ontology the idea has the highest reality and all derived instances have a lower grade of reality through limitations of it, God as the sum-total of all ideas is the most real being (ens realissimum). Second, God causally grounds the actuality of contingent things. This distinction is continuous with the Leibnizian distinction employed earlier in OPA between God's understanding and God's will. Thus I argue that the way Kant introduces the notion of Platonic ideas as productive archetypes illuminates the same grounding relation between God and possibilities as was presented in the pre-Critical period.

Regarding the way possibilities are grounded, how does this account compare with the Spinozistic reading? Chignell argues that, as a final account of possibility, appealing to the 'attributes of an absolutely necessary being' is more explanatorily satisfactory than appealing God's thought, which seems to require a further explanation (Chignell 2014: 67). I disagree for the following reason. As an explanation of truths about possibilities, Exemplification seems to be based on the implication that actuality entails possibility. ${ }^{34}$ Therefore this account really explains modality away by reducing modal facts to non-modal facts about properties of God. ${ }^{35}$ But since the properties exemplified in God are not of a different kind than instances of exemplified properties in general, Exemplification does not clearly express what Kant seeks in his 
discussions of teleology and causality, namely, the explanation of the lawfulness exhibited by particular instances. According to my reading, modal facts are explained as a relation of instances to universal essences, the kind of entities posited to explain the possibility of things as the type of things they are and their possible relations to things of other types. ${ }^{36}$ Thus the notion of a Platonic idea, mysterious as it might be, provides a superior explanation for the lawfulness that Kant relates to the conception of God as the ground of possibility.

If possibilities are grounded in Platonic essences and not in exemplification of properties, we should not be misled by Kant's image that God provides the 'material' ${ }^{37}$ for possibility into thinking that properties are instantiated by God so that the totality of actual things after all inheres in God. This also means that the co-existence of essences in one mind should not be conflated with their co-instantiation in one substance, as Spinozism demands. Kant later uses another metaphor for God as containing 'the wherewithal for the creation of all other possible things, as the marble quarry does for statues of infinite diversity' (PM 20:302; emphasis mine). ${ }^{38}$ To continue with the metaphor, the same marble quarry provides material for infinitely many possible statues by providing material for different combinations of pieces cut from it. This means that several things can share the same chunk of marble, and therefore we cannot think of the marble as containing the totality of all actual statues. Thus I suggest interpreting 'the material of possibility' metaphor as referring to metaphorical building blocks from which God can choose to create actual things as instantiations of different combinations from the same blueprints.

One of the merits of Chignell's interpretations is that it provides resources for defending Kant's conclusion to the uniqueness of God against the objection that there could be a plurality of beings together grounding all possibility (the plurality objection). He argues that only the exemplification of all predicates in one being can ground the relations of real harmony and 
repugnance between possibilities. This solution to the plurality objection also rules out the Leibnizian option because thought, even divine thought, cannot track relations of real harmony. ${ }^{39}$ Addressing the challenge of the plurality objection in response to Chignell, Yong argues that his Leibnizian interpretation can also appeal to the need to ground relations as a way to reconstruct Kant's argument, by showing that all possibilities must be thought as related in one mind. Furthermore, Yong shows that Kant used similar considerations in his account of causality (Yong 2014: 38-44). Indeed, there is a similar argument in Leibniz regarding the need to ground relations between necessary truths in one mind (Adams 1994: 180-2). My more specific metaphysical picture, appropriating the notion of Platonic ideas, provides further support for Yong's way of responding to the plurality objection. Since Platonic ideas are tied to the notion of an intuitive intellect, Chignell's claim that divine cognition cannot account for relations of real harmony is unjustified. While for human cognition the matter of concepts must be given through sensibility and therefore thought can only track the logical relations between concepts, intellectual intuition is the type of cognition that has a priori insight into the content of the essences of things and thus also into the possible relations between them.

Another objection to the Leibnizian reading is based on Kant's mature conception of divine cognition (Chignell 2012: 671). Kant describes God's cognition as an intuitive intellect, i.e. an immediate, singular and productive representation of things, in contrast with human finite cognition which on the one hand is mediated by abstract concepts and on the other hand passively affected through sensible intuition (ID 2: 396-7). Thus God's intellectual intuition represents only (and all) actuality and not un-actualized possibilities (CJ 5: 401-2). But this does not mean that divine cognition represents the actuality of things in the human way of intuiting particulars. Kant describes God's intellect in the following way: 'His cognitions are intuitions 
and not concepts; not sensible intuitions, but ideas; these do not presuppose things, but make them possible' (R6041, 18: 431, my translation and emphases). This explanation of intellectual intuition shows that by intuiting Platonic ideas, i.e. the intelligible and productive archetypes of things, God represents at the same time all their possible instances. Thus the discursive distinction between possibility and actuality, which is based on the subjective distinction between what is given in sensation in what is merely thought, is inapplicable for a divine mind, ‘in which possibility and actuality can no longer be distinguished at all’ (CJ 5: 402). But by using the notion of Platonic ideas, we might speculate about an ontological distinction between essences and their instances, though how it relates to the sensible world is for the Critical Kant beyond the boundaries of possible knowledge. ${ }^{40}$

Finally, the metaphysical picture expounded above provides a straightforward explanation of the fate of the possibility proof in the Critical philosophy. The conception of God as the ground of all possibilities is construed in terms of the notion of a sum-total of Platonic essences and is therefore of an intuitive intellect comprehending it. For the pre-Critical Kant, the starting assumption that there are intelligible essences underlying the possibility of things perceived in the world was innocuous. Given such essences, Kant found it unproblematic to prove the existence of a necessary being uniting them. For the Critical Kant, insight into the inner possibility, i.e. the intelligible essence of things, is impossible for human thought, whose only grip on the possibility of things is through the sensibly given. Therefore the starting point for the possibility proof cannot be presupposed as given. Yet the proof is still subjectively valid 'from the concession that we can judge a priori about this [inner possibility]' (R5508, 18: 203), meaning that the idea of God expresses what is sought in a conceptual explanation of 'what in general the possibility of something consists in’ (28: 1034). Even though intelligible essences are 
not an object of knowledge, because they explain possibility and moreover guide scientific inquiry, human reason has a legitimate interest in assuming their existence, and consequently in assuming their systematic unity as expressed by the regulative idea of God.

\section{Conclusion}

From 1755, through 1763 and until 1770, we find a rather consistent view of the role of God in grounding the unity and lawfulness of essences in nature. This is more consistent with the Leibnizian view (and Kant's later Platonistic conception) of grounding possibilities as essences in the divine mind than with the Spinozistic view that unifies God and the totality of actual things. It is possible that Kant's realization that his pre-Critical Leibnizian view is inconsistent was among the motivating reasons for the Critical turn. Such a realization is also consistent with his later remark that 'Spinozism is the true consequence of dogmatic metaphysics' (R6050, 18: 436), which does not imply that his own dogmatic metaphysics entailed Spinozism. The Critical Kant could concede that, overall, Spinoza's system is more consistent than Leibniz's, while still maintaining that the Leibnizian conception of God is the correct one in the sense that it expresses a legitimate interest of reason in regarding all possibility as grounded in Platonic ideas united in one mind. In contrast with the Dissertation, in the first Critique Kant no longer thought that intelligible essences are objects of knowledge and argued that the sensible world has conceptual conditions of unity without appealing to the existence of God. Yet he still held that the conceptual unity as expressed in the idea of God serves as a regulative ideal for seeking lawfulness in nature. Thus the main distinction between God as the ground of possibility and the actual world, the distinction that is incompatible with Spinozism, continues to play a role in the Critical system. Paying attention to this distinction can therefore illuminate an aspect in the development of Kant's thought that the Spinozistic reading cannot, namely, that one of the 
motivations for adopting transcendental idealism was finding a coherent picture that retains the pre-Critical Leibnizian conception of God as grounding the unity of essences, together with the anti-Leibnizian conception of empirical knowledge of the actual world. ${ }^{41}$

\section{Notes}

${ }^{1}$ I cite Kant from the Akademie edition by reference to volume and page number. Quotations from Critique of Pure Reason are cited by the standard (A/B) pagination. I mostly use the translations of the Cambridge edition of Kant's works (Kant 1998, Kant 2000, Kant 2001 [LPR], Kant 2002 [PM], Kant 2003 [NE, OPA, ID], Kant 2005 [Reflexionen]); if there has been no translation in that edition, translations are mine. References to Kant's unpublished Reflexionen will be given with the numbers of the individual reflections $(\mathrm{R} \#)$ provided in the volumes 17, 18 and 19 of the Akademie edition. I will use the following abbreviations: OPA= The Only Possible Argument in Support of a Demonstration of the Existence of God; NE=A New Elucidation of the First Principles of Metaphysical Cognition; ID=On the Form and Principles of the Sensible and the Intelligible World [Inaugural Dissertation]; CJ=Critique of the Power of Judgment; PM=What Real Progress has Metaphysics Made in Germany since the Time of Leibniz and Wolff?; LPR=Lectures on the Philosophical Doctrine of Religion. Quotes and citations of other authors: Leibniz’s Monadology from Leibniz 1989; Baumgarten’s Metaphysica from Baumgarten 2013; Wolff's Deutsche Metaphysik from Wolff 1983.

2 Boehm 2012, Chignell 2012. Responses by Abaci 2014, Yong 2014, and Wyrwich 2014.

${ }^{3}$ Henceforth, the possibility proof.

${ }^{4}$ I will address the question whether the argument is sound only insofar as different stances on this question relate to the issue of Spinozism. 
${ }^{5}$ Chignell 2012 adds another condition, which he dubs 'Harmony'. I will address this issue later on.

${ }^{6}$ For reconstructions of the proof and criticism of this particular point see among others Wood 1978: 70-1, Adams 2000: 433-5, Schönfeld 2000: 207, Stang 2010: 293-4. Chignell 2012 offers a Spinozistic solution which will be discussed below.

${ }^{7}$ See also Newlands 2013: 157.

${ }^{8}$ See also Leibniz’s Theodicy \$184 (Leibniz 1985: 243-4).

${ }^{9}$ For example Wood 1978: 67: 'for a reality to be an object of thought it must be instantiated somewhere in an existing thing' (emphasis mine). Logan 2007 seems to support this view.

Others such as Fisher and Watkins 1998 and Schönfeld 2000 are rather vague about the nature of the grounding relation and do not see important differences between Leibniz and Kant on this point. Stang 2010 and Yong 2014 explicitly reject Exemplification.

${ }^{10}$ This is Stang's interpretation of the argument (2019: 290-1), that possibilities are grounded in God in virtue of his possessing powers to produce instances.

${ }^{11}$ This is the interpretation in Chignell 2009.

${ }^{12}$ Boehm 2012: 301. In contrast I will argue that Kant follows Leibniz in distinguishing between God's will as the cause of existence and God's intellect as the ground of possibility.

${ }^{13}$ I will provide my alternative interpretation to the image of limitation in section 2.4.

${ }^{14}$ Against Boehm, Wyrwich 2014 points to the many places in which Kant explicitly rejects Spinozistic conceptions of God and substance. This, however, does not exclude the possibility that Kant's argument in OPA in itself entails Spinozism.

${ }^{15}$ In other words the transition from 'necessarily (de dicto), something (or other) exists' to "' 'there is one being that necessarily (de re) exists'. 
16 The textual and philosophical grounds for interpreting Kant's argument in terms of the harmony requirement have been criticized in Abaci 2014 and Yong 2014. In section 2.4 I will refer to Yong’s response, which fits my reading as well.

${ }^{17}$ Chignell 2012: 669. In section 2.4 I address this claim.

${ }^{18}$ For a detailed interpretation of Leibniz's position regarding the ground of possibility, see Newlands 2013: 164-6. In contrast with Newlands, who reads Kant in terms of Exemplification, I argue here that the Leibnizian view is roughly also the Kantian view.

${ }^{19}$ Leibniz 2006: 182 ('On necessary or eternal truths’).

20 There is a similar argument in §221 of Crusius' Sketch of the Necessary Truths of Reason 'We find in the world an orderly and regular connect ion and sequence of things that apparently lead us [to the idea] that it was formed according to ideas and has an intelligible cause' (in Watkins 2009: 167).

${ }^{21}$ In section 2 of OPA Kant provides ample examples for such harmony in geometry, mechanics, astronomy, etc.

${ }^{22}$ For Leibniz necessary truths are grounded in God's intellect and follow necessarily from the nature of God's mind, unlike contingent truths which are dependent on God's free will (Monadology §46). Kant follows Leibniz in characterizing necessity and contingency in this way: 'Anything, the ground of which has to be sought in a free choice must, for that very reason, be contingent’ (OPA 2: 101).

${ }^{23}$ In Kant: 'these [harmony and adaptedness] are characteristics which must, in the first place, be found in the possibilities of things. It is only afterwards that wisdom can then become active in choosing them’ (OPA 2: 151; emphasis mine). 
24 'the necessity of these laws [of motion] is such that they can be derived from the universal and essential constitution of all matter’ (OPA 2: 99).

${ }^{25}$ Yong 2014: 42 makes a similar point.

${ }^{26}$ The term used in the 'Lectures on the Philosophical Doctrine of Religion’ (LPR 28:1037ff.).

${ }^{27}$ For a full account of Kant's pre-Critical theory of causality and its relation to the debates of the $18^{\text {th }}$ century see Watkins 1995 and Watkins 2005: ch. 2.

${ }^{28}$ More about this point in Watkins 2005: 174.

${ }^{29}$ This implies that the intelligible world inheres in God's mind. I believe that this understanding is relevant also for interpreting the notion of an intelligible world in the Critical system, but discussing this is beyond the scope of this paper. It should be noted, however, that in 1770 Kant still thought that God, and hence the intelligible world, can be objectively known to exist. 30 This Neo-Platonic understanding of Plato was perhaps influenced by Jakob Brucker's book on the history of philosophy which Kant read. See Serck-Hanssen and Emilsson 2004: 72.

${ }^{31}$ For example R6050 (18:434), R6611 (19:108), ID 2: 413.

${ }^{32}$ In a letter to Hansch Leibniz expressed a similar approval of some of the platonic doctrines, mainly 'that there is an intelligible world in the divine mind, which I also usually call the region of ideas’ (Leibniz 1976: 592).

${ }^{33}$ For example R3825, 4124, 4270 (17: 304, 426, 489), and Platonism specifically in R4346-8, 4604, 6050 (17: 514-5, 607; 18: 434). Kant concludes the lecture on these sections of Baumgarten with a paragraph about Platonic ideas (LPR 28: 1058-9). In the first Critique a discussion of Platonic ideas also prefaces the exposition of the concept of God as the ideal of reason (A568/B596). In some places Kant remarks that the significance of the Leibnizian philosophy lies in its Platonistic conception of an intelligible world (Metaphysical Foundations 
of Natural Science 4: 507, On a Discovery whereby any New Critique of Pure Reason is to be Made Superfluous by an Older One 8: 248).

${ }^{34}$ Making the reverse inference from possibility to actuality is of course fallacious, but Chignell argues that Kant's strategy is to rule out all other alternatives, leaving exemplification as the only possible ground (Chignell 2009: 180).

${ }^{35}$ For a similar point see Stang 2010: 297. In a sense my interpretation qualifies Stang’s position about God's powers as the ground of possibility, and distinguishes between the intellectual power, which is identical with being a subject of ideas, which grounds possibility, and the causal power that grounds actuality.

${ }^{36}$ For a contemporary defence of Platonism as an explanation of modal truths see Berman 2013.

${ }^{37}$ For example in OPA 2: 100 and at A575/B603.

${ }^{38}$ Boehm quotes the rest of the passage as further evidence that Kant was aware that the conception of God endorsed by him leads to Spinozism (Boehm 2012: 306). But Kant does not claim here that this conception necessarily leads to Spinozism, only that it is possible to derive from it the identity of God and the world.

${ }^{39}$ See Newlands 2013: 182-3 for a reply on behalf of Leibniz.

${ }^{40}$ Discussing Kant's position regarding possible worlds in the Leibnizian sense is beyond the scope of this paper. My aim is to show that, similarly to Leibniz, essences in God's mind ground possibilities rather than exemplified predicates, and that in this aspect there is continuity in Kant's thought.

${ }^{41}$ For invaluable comments on earlier versions of this essay, I am especially indebted to Allen Wood, Sandra Shapshay and two anonymous referees for Kantian Review. I am also grateful to Tobias Rosefeldt, Ido Geiger, Michael Oberst, Toni Kannisto and other participants of the 
Colloquium for Classical German Philosophy at Humboldt Universität zu Berlin in which an earlier version of this paper was presented.

\section{References}

Abaci, Uygar (2014) ‘Kant’s Only Possible Argument and Chignell’s Real Harmony’. Kantian Review, 19/1, 1-25.

Adams, Robert Merrihew (1994) Leibniz: Determinist, Theist, Idealist. Oxford: Oxford University Press. 2000) ‘God, Possibility, and Kant'. Faith and Philosophy, 17/4, 425-40.

Baumgarten, Alexander (2013) Metaphysics: A Critical Translation with Kant's Elucidations, Selected Notes, and Related Materials. Trans. Courtney D. Fugate and John Hymers. New York: Bloomsbury Publishing.

Berman, Scott (2013) ‘A Platonic Theory of Truthmaking’. Metaphysica, 14/1, 109-25.

Boehm, Omri (2012) ‘Kant’s Regulative Spinozism’. Kant-Studien, 103/3, 292-317.

Chignell, Andrew (2009) 'Kant, Modality, and the Most Real Being’. Archiv für Geschichte der Philosophie, 91/2, 157-92. (2012) 'Kant, Real Possibility, and the Threat of Spinoza'. Mind, 121/483, 635-75. (2014) 'Kant and the “Monstrous” Ground of Possibility’. Kantian Review, 19/1, 53-69.

Fisher, Mark, and Watkins, Eric (1998) 'Kant on the Material Ground of Possibility: From “The Only Possible Argument” to the "Critique of Pure Reason” '. Review of Metaphysics, 52/2, 369-95.

Kant, Immanuel (1998) Critique of Pure Reason. Trans. Paul Guyer and Allen W. Wood. Cambridge: Cambridge University Press. 
(2000) Critique of the Power of Judgment. Trans. P. Guyer and E. Matthews. Cambridge: Cambridge University Press.

(2001) Religion and Rational Theology. trans. A.W. Wood and G. di Giovanni.

Cambridge: Cambridge University Press.

(2002) Theoretical Philosophy after 1781. Trans. H. Allison, P. Heath, G. Hatfield and M.

Friedman. Cambridge: Cambridge University Press.

(2003) Theoretical philosophy, 1755-1770. Trans. David Walford and Ralf Meerbote.

Cambridge: Cambridge University Press.

(2005) Notes and Fragments. Trans. P. Guyer, C. Bowman and F. Rauscher. Cambridge:

Cambridge University Press.

Leibniz, G.W.F. (1976) Philosophical Papers and Letters: A Selection. Trans. L.E. Loemker.

Dordrecht: Springer Netherlands.

(1985) Theodicy: Essays on the Goodness of God, the Freedom of Man, and the Origin of

Evil. Trans. E.M. Huggard. La Salle, Ill. : Open Court.

(1989) Philosophical Essays. Trans. R. Ariew and D. Garber. Indianapolis: Hackett

Publishing Company.

(2006) The Shorter Leibniz Texts: A Collection of New Translations. Trans. L. Strickland.

New York: Bloomsbury Publishing.

Logan, Ian (2007) 'Whatever Happened to Kant’s Ontological Argument?'. Philosophy and Phenomenological Research, 74/2, 346-63.

Newlands, Samuel (2013) ‘Leibniz and the Ground of Possibility’. Philosophical Review, 122/2, $155-87$. 
Schönfeld, Martin (2000) The Philosophy of the Young Kant: The Precritical Project. Oxford: Oxford University Press.

Serck-Hanssen, Camilla, and Emilsson, Eyjólfur K. (2004) ‘Kant and Plato’. SATS: Northern European Journal of Philosophy, 5/1, 71-82.

Stang, Nicholas F. (2010) ‘Kant’s Possibility Proof’. History of Philosophy Quarterly, 27/3, 27599.

Watkins, Eric (1995) 'Kant’s Theory of Physical Influx’. Archiv für Geschichte der Philosophie, 77/3, 285-324. (2005) Kant and the Metaphysics of Causality. Cambridge: Cambridge University Press. (2009) Kant's Critique of Pure Reason: Background Source Materials. Cambridge: Cambridge University Press.

Wolff, Christian (1983) Gesammelte Werke: Deutsche Schriften. Vernünfftige Gedancken. - 2. Vernünfftige Gedancken von Gott, der Welt und der Seele des Menschen, auch allen Dingen überhaupt (Deutsche Metaphysik). Hidesheim: Olms.

Wood, Allen W. (1978) Kant’s Rational Theology. Ithaca, N.Y.: Cornell University Press. Wyrwich, Thomas (2014) ‘Kants Anti-Spinozismus - Eine Antwort auf Omri Boehm’. KantStudien, 105/1, 113-24.

Yong, Peter (2014) ‘God, Totality and Possibility in Kant’s Only Possible Argument’. Kantian Review, 19/1, 27-51. 